\title{
Alternative fabrication scheme to study effects of rework of nonconforming products and delayed differentiation on a multiproduct supply-chain system
}

\author{
Yuan-Shyi Peter Chiu ${ }^{a}$, Hong-Dar Lin ${ }^{a}$, Mei-Fang $W^{b}$ and Singa Wang Chiu ${ }^{c^{*}}$
}

${ }^{a}$ Department of Industrial Engineering \& Management, Chaoyang University of Technology, Wufong District, Taichung 413, Taiwan

${ }^{b}$ Department of Industrial Engineering \& Systems Management, Feng Chia University, Taichung, Taiwan

${ }^{c}$ Department of Business Administration, Chaoyang University of Technology, Wufong District, Taichung 413, Taiwan

C H R O N I C L E

\section{Article history:}

Received January 152017

Received in Revised Format April 12017

Accepted June 12017

Available online

June 12017

Keywords:

Multiproduct system

Cleaner production

Rework of nonconforming items

Delay product differentiation

Two-machine scheme

Multi-delivery plan

\section{A B S T R A C T}

\begin{abstract}
This study uses an alternative fabrication scheme to study the effect of rework of nonconforming items and delayed differentiation on a multiproduct supply-chain system. Traditional economic production quantity model focuses on a single-product inventory system where all products made are assumed to be perfect quality and finished products are issued continuously. To increase machine utilization, lower quality costs in production, and reflect the real-world vendor-buyer integrated systems Chiu et al. (2016a) [Chiu, Y-S.P., Kuo, J-S., Chiu, S. W., Hsieh, Y-T. (2016a). Effect of delayed differentiation on a multiproduct vendor-buyer integrated inventory system with rework. Advances in Production Engineering \& Management, 11(4), 333-344.] employed a single-machine two-stage production scheme to study the effects of rework and delayed differentiation on a multi-product supply-chain system. With the intention of further reducing fabrication cycle time, this study considers an alternative two-machine two-stage fabrication scheme to re-explore the problem in Chiu et al. (2016a). Machine one solely produces all common parts for multiple end products. Then, machine two fabricates the customized multiproduct using a common cycle time strategy. Through the use of mathematical modeling and analyses, the optimal production cycle length and distribution policy are derived. Numerical examples are provided to demonstrate practical usage of the research results, and show its significant benefit in reducing fabrication cycle time compared to that obtained from prior studies that used different schemes.
\end{abstract}

\section{Introduction}

In contrast to conventional economic production quantity (EPQ) model that focuses on a perfect fabrication of a single product with continuous stock supplying policy, in most manufacturing environments, fabrication of multiproduct under a common cycle time policy is often utilized to effectively increase machine utilization (Rosenblatt \& Rothblum, 1990; Aliyu \& Andijani, 1999; Hillier \& Lieberman, 2001; Caggiano et al., 2009; Nahmias, 2009; Guerrero et al., 2013; Fergany, 2016; Chiu et al., 2016b; Zahedi, et al., 2016). Extra studies have been focused on issues of inevitable imperfect product quality and their consequent quality assurance matters (Henig \& Gerchak, 1990; Rahim \& BenDaya, 2001; Ma et al., 2010; Chiu et al., 2015; Karunambigai et al., 2015; Boorla \& Howard, 2016; Gómez et al., 2016; Jawla \& Singh, 2016).

* Corresponding author

E-mail: swang@cyut.edu.tw (S. W. Chiu)

(C) 2018 Growing Science Ltd. All rights reserved. doi: $10.5267 /$ j. ijiec.2017.6.001 
In real-life vendor-buyer integrated inventory systems, the periodic/multiple delivery policy is commonly adopted for distribution of the end products (Schwarz et al., 1985; Sarker \& Parija, 1994; Thomas \& Hackman, 2003; Archetti et al., 2013; Balaji et al, 2015; Kundu \& Chakrabarti, 2015). When multiproduct sharing a common intermediate part, production managers would often evaluate various potential production schemes seeking to cut down overall manufacturing costs and/or production cycle time, e.g., assessment of a two-stage fabrication scheme (wherein stage one makes all common parts for multiple end items, and stage two fabricates the customized multiproduct), versus conventional singlestage production scheme. Studies showed that the redesigning a multiproduct fabrication system with delayed product differentiation has been an effective supply chain strategy for saving cost and reducing response time. Collier (1982) conducted simulation experiments to investigate relationship between aggregate safety stocks and component part commonality in an unsure operating situation. Swaminathan and Tayur (1999) pointed out that one way for producers to stay competitive is to provide large variety in the product line by integrating their product design and operations. They believed that by improving assembly sequence, the producers can gain a better operational response to customer demands. Therefore, a few integrated models were proposed with the aim of providing operational benefits. Qualitative insights on various issues are also provided thru their computational illustrations, e.g., the effect of products' features, setup times, life cycles, and demand variation on optimal assembly design, etc. Graman and Magazine (2006) conducted interviews with corporation managers with the aim of identifying the main issues that may affect the implementation of postponement strategy. They discovered that more issues were related to implementation of a partial postponement strategy than reposition of inventories as recommended by mathematical model. They identified that operations scheduling, product integrity, and organizational readiness are main issues that influence most on implementing postponement. Reimann (2012) proposed a stylized model for a product with uncertain demand during a short selling season and studied the effect by adopting the postponement. It is assumed that the vendor has three different supply options as follows: (1) vendor can fabricate and offer a standard version product; (2) vendor can adopt the postponement strategy by producing the common component first, and customizing the end product once customer demands are received; and (3) vendor can produce the customized products based on a single-stage make-to-order production mode during the selling season. The results from three different options can help management in better decision making. Chiu et al. (2016a) used mathematical modeling to explore a single- machine two-stage multiproduct vendorbuyer integrated inventory system with rework, wherein all common parts needed for all products are fabricated in stage one, and end products are produced sequentially under a common production cycle time policy in stage two, both on a single machine. Their objective was to cut down the system cost and reduce the production cycle time as compared to what was obtained from a single stage production system. As a result, they derived the closed-form optimal replenishment cycle time and delivery decisions and showed that their two-stage fabrication production system with delayed differentiation is considerably beneficial vis-à-vis single-stage scheme in cost saving and cycle time reduction. Chiu et al. (2016c) further extended the same model of Chiu et al. (2016a) with extra features on random scrap rates existence in both regular fabrication and rework processes for both common part's and end products' fabrication stages using single-machine production scheme. Prior literatures regarding different aspects of the postponement strategy used in multiproduct fabrication systems can also be found elsewhere (Gerchak and Henig, 1986; Lee, 1996; Swaminathan and Tayur, 1998; Graman and Magazine, 2002; Gupta and Benjaafar, 2004; Weber, 2008; Bernstein et al., 2011; Ferreira et al., 2015).

With the aim of further shortening replenishment cycle time, this study proposes a two- machine fabrication scheme to reexamine the problem studied by Chiu et al. (2016a). With the aim of further shortening production cycle time, this study proposes an alternative two-machine production scheme to reexamine the problem studied in Chiu et al. (2016a). Machine one solely produces all common parts for multiple end products. Then, machine two fabricates the customized multiproduct using a common cycle time strategy. Using the mathematical modeling and optimization approaches, the closed-form optimal production cycle time and delivery decisions are determined. Numerical examples are provided to demonstrate practical usage of the obtained results, and show its significant benefits in reducing 
production cycle time as compared to that obtained from prior studies that used different schemes. Detailed problem statements, mathematical modeling, and the solution procedure are presented in the following sections.

\section{The proposed two-machine multiproduct fabrication scheme}

This section presents assumptions and mathematical modeling of the proposed study. Assume $L$ diverse products (where $i=1,2, \ldots, L$ ) sharing a mutual part are to be produced using a two-machine fabrication scheme. Machine one (i.e., the stage one) solely produces the common parts for all end products at a rate of $P_{1,0}$ (see Fig. 1). Then, machine two (i.e., the stage two) fabricates $L$ diverse products at annual rate of $P_{1, i}$, using a common cycle length strategy (see Fig. 2). The objectives of the production-distribution plan are to meet annual demand rates $\lambda i$, shorten fabrication cycle length, and minimize overall relevant costs.

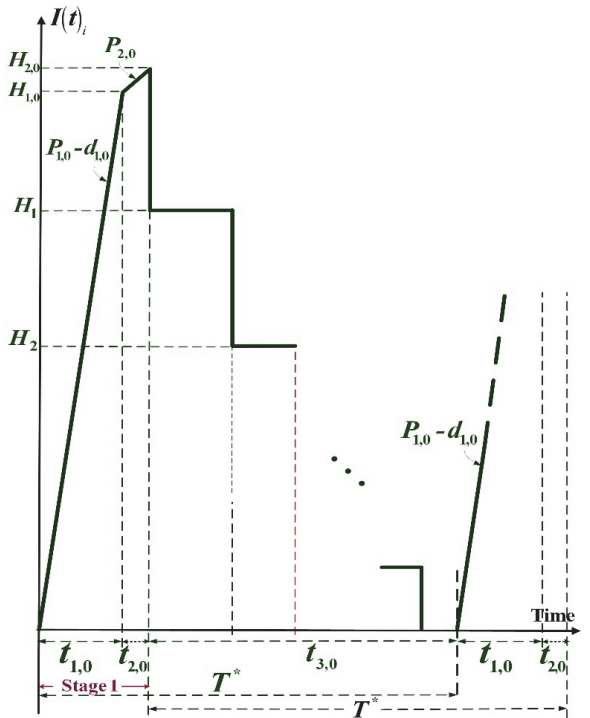

Fig. 1. On-hand inventory level of perfect quality common parts in stage one of the proposed two-machine two-stage fabrication scheme

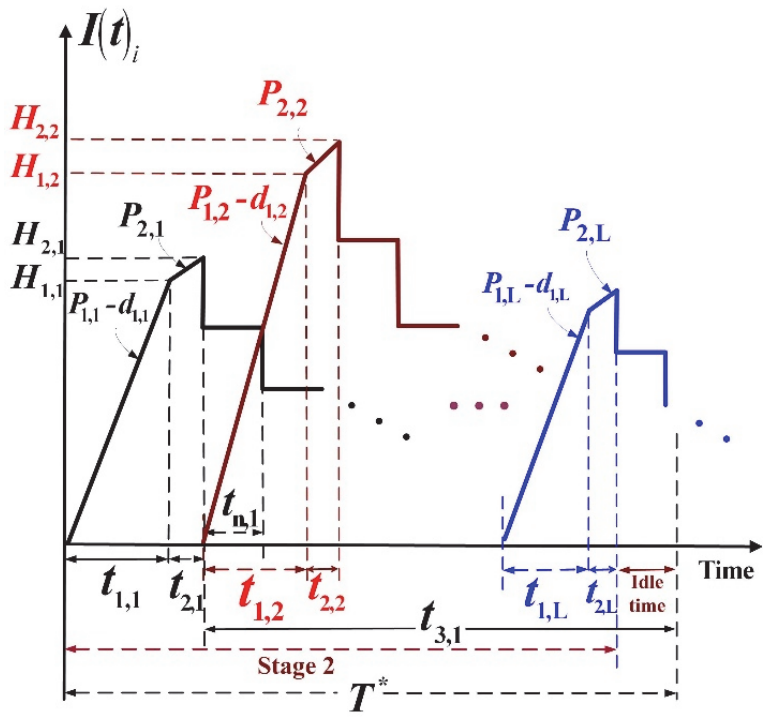

Fig. 2. On-hand inventory level of perfect quality $L$ customized end products in stage two of the proposed twomachine two-stage fabrication scheme

Under quality screening, random defective rate $x_{i}$ is observed in both production processes (where $i=0$, $1,2, \ldots, L$; and $i=0$ stands for its status of stage one when all common parts were produced by machine one). Defective items are produced at a rate of $d_{1, i}$. It is assumed that all defective items can be repaired by a follow-up rework process, at a rate of $P_{2, i}$, right after the end of regular production processes (see Figs. 1 to 3$)$. To disallow shortages, this study assumes $\left(P_{1, \mathrm{i}}-d_{1, \mathrm{i}}-\lambda_{i}\right)>0$.
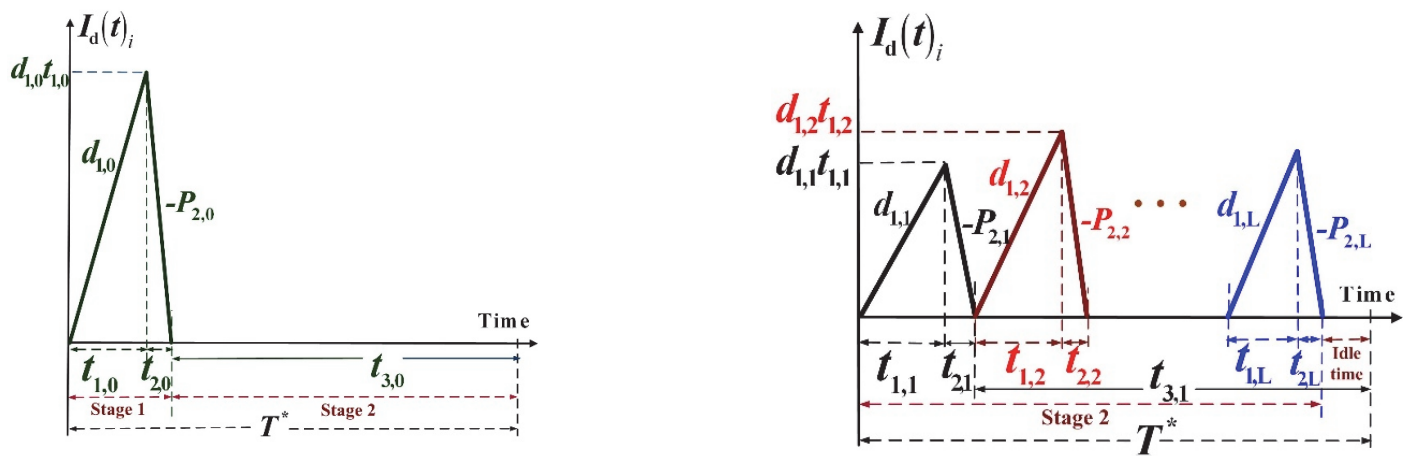

Fig. 3. On-hand inventory levels of defective common intermediate parts in stage one (left) and defective customized end products in stage two (right) 
In the end of stage one, $L$ different lots of the common parts become ready for the second stage's fabrication, where machine two produces $L$ end items in order using a common cycle time strategy (Fig. 2). The on-hand stock level of common parts waiting to be processed into customized finished items (by machine two) is illustrated in Fig. 4.

In stage two, for each end product $i$ (where $i=1,2, \ldots, L$ ), when rework process $t_{2, i}$ ends, $n$ fixed quantity installments of the completed batch are distributed to customer, at a fixed interval of time in $t_{3, \mathrm{i}}$ (see Fig. 2). The on-hand level of the stocks at buyer's end in a replenishment cycle is depicted in Fig. 5. Extra notation employed in the present study is provided in Appendix A.

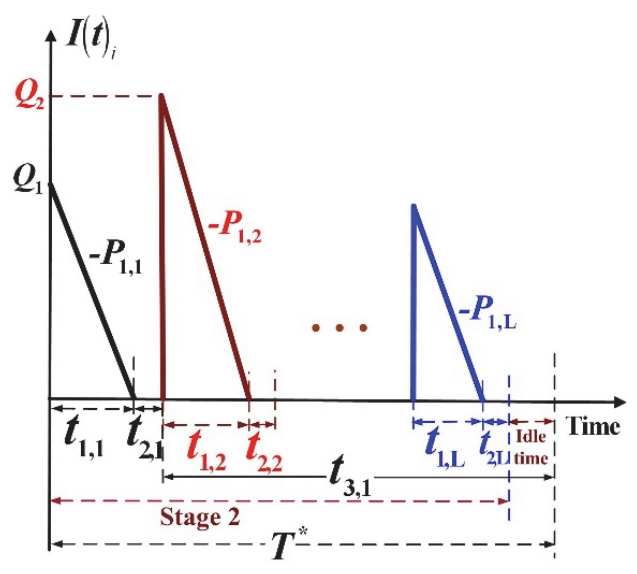

Fig. 4. On-hand inventory level of common parts waiting to be fabricated into customized end products in stage 2 of the proposed study

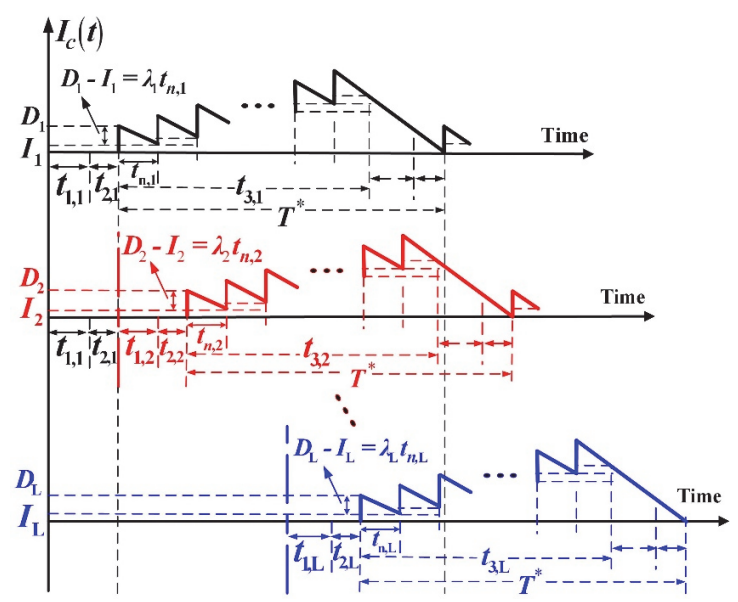

Fig. 5.On-hand inventory level of customized end products at the customer's side during the production cycle

The proposed two-machine multiproduct fabrication scheme with postponement, aims at releasing the production workload of common parts from machine two. Therefore, the proposed scheme should have a more efficient result on fabricating customized end products in the second stage. The proposed solution process starts with determining the optimal common production cycle time for machine two, and then applying the obtained cycle length to machine one for production of all common parts in advance (see both Figs. 1 and Fig. 2). The following prerequisite condition must satisfy to ensure that machine two has sufficient capacity to fabricate and rework all $L$ products under a common cycle length discipline:

$$
\sum_{i=1}^{L}\left(t_{1, i}+t_{2, i}\right)<T \text { or } \sum_{i=1}^{L} Q_{i}\left[\frac{1}{P_{1, i}}+\frac{E\left[x_{i}\right]}{P_{2, i}}\right]<T
$$

or

$$
\sum_{i=1}^{L} \lambda_{i}\left[\frac{1}{P_{1, i}}+\frac{E\left[x_{i}\right]}{P_{2, i}}\right]<1
$$

In stage two, the proposed fabrication must meet demand rate $\lambda_{i}$ of $L$ diverse product $i$ (where $i=1,2, \ldots$, $L)$, the basic formulas displayed in Appendix B can be observed directly from Figs. 2 to $5 . T C_{2}(T, n)$ consists of fabrication variable and setup costs, reworking costs, the fixed and variable transportation costs, and total inventory holding costs for perfect and imperfect items in $t_{1, i}$ and $t_{2, i}$, for reworked items in $t_{2, i}$, for stocks stored at customers' side, and for safety stocks in the production cycle. So, $T C_{2}(T, n)$ is as follows: 


$$
T C_{2}(T, n)=\sum_{i=1}^{L}\left\{\begin{array}{l}
C_{i} Q_{i}+K_{i}+C_{R, i}\left(x_{i} Q_{i}\right)+n K_{1, i}+C_{T, i} Q_{i}+h_{2, i}\left(\frac{P_{2, i} t_{2, i}}{2}\right)\left(t_{2, i}\right) \\
+h_{1, i}\left[\frac{Q_{i}}{2}\left(t_{1, i}\right)+\frac{H_{1, i} t_{1, i}}{2}+\frac{H_{2, i}+H_{1, i}}{2}\left(t_{2, i}\right)+\left(\frac{n-1}{2 n}\right) H_{2, i} t_{3, i}+\frac{d_{1, i} t_{1, i}}{2}\left(t_{1, i}\right)\right] \\
+h_{3, i}\left[\frac{n\left(D_{i}-I_{i}\right) t_{n, i}}{2}+\frac{n(n+1)}{2} I_{i} t_{n, i}+\frac{n I_{i}\left(t_{1, i}+t_{2, i}\right)}{2}\right]+h_{4, i}\left(x_{i} Q_{i}\right) T
\end{array}\right\}
$$

Substitute Eqs. (B-1) to (B-12) in Eq. (3) and take into account of randomness of $x_{i}$ by using the expected values of $x$, and with further derivation, $\mathrm{E}\left[T C U_{2}(T, n)\right]$ can be obtained as follows:

$$
\begin{aligned}
& E\left[T C U_{2}(T, n)\right]=E\left[T C_{2}(T, n)\right] / E[T] \\
& =\sum_{i=1}^{L}\left\{\begin{array}{l}
{\left[C_{i} \lambda_{i}+\frac{K_{i}}{T}+C_{R, i} \lambda_{i} E\left[x_{i}\right]+\frac{n K_{1, i}}{T}+C_{T, i} \lambda_{i}\right]+\frac{h_{1, i} T \lambda_{i}^{2}}{2}\left\{\beta_{2, i}-\frac{\beta_{1, i}}{n}\right\}} \\
+\frac{h_{2, i} T \lambda_{i}^{2} E\left[x_{i}\right]^{2}}{2 P_{2, i}}+\frac{h_{3, i} T \lambda_{i}^{2}}{2}\left[\frac{1}{P_{1, i}}+\frac{E\left[x_{i}\right]}{P_{2, i}}+\frac{\beta_{1, i}}{n}\right]+T h_{4, i} \lambda_{i} E\left[x_{i}\right]
\end{array}\right\}
\end{aligned}
$$

where

$$
\beta_{1, i}=\left[\frac{1}{\lambda_{i}}-\frac{1}{P_{1, i}}-\frac{E\left[x_{i}\right]}{P_{2, i}}\right] \text { and } \beta_{2, i}=\left[\frac{1}{\lambda_{i}}-\frac{E\left[x_{i}\right]^{2}}{P_{2, i}}+\frac{1}{P_{1, i}}+\frac{E\left[x_{i}\right]}{P_{2, i}}\right] \text { for } i=1,2, \cdots, L \text {. }
$$

In stage one, machine one has to make enough common parts in advance for the fabrication of $L$ diverse end products. Hence, machine one must start producing common parts $\left(t_{1,0}+t_{2,0}\right)$ ahead of time (see Fig. 1). The basic formulas displayed in Appendix $\mathrm{C}$ can also be observed directly from Fig. 1, Fig. 3, and Fig. 4. Similarly, machine one must have sufficient capacity to produce and rework all common intermediate parts. That is, the following prerequisite condition must satisfy:

$$
\left(t_{1,0}+t_{2,0}\right)<T \text { or }\left[\left(\frac{Q_{0}}{P_{1,0}}+\frac{E\left[x_{0}\right] Q_{0}}{P_{2,0}}\right)\right]<T
$$

or

$$
\left[\frac{\lambda_{0}}{P_{1,0}}+\frac{E\left[x_{0}\right] \lambda_{0}}{P_{2,0}}\right]<1
$$

Total relevant fabrication costs per cycle for stage one, $T C_{1}(T, n)$ consists variable production cost, setup cost, reworking cost, and total inventory holding costs for perfect and imperfect items in $t_{1,0}$ and $t_{2,0}$, for reworked items in $t_{2,0}$, and for the safety stocks. So, $T C_{1}(T, n)$ is

$$
T C_{1}(T, n)=\left\{\begin{array}{l}
C_{0} Q_{0}+K_{0}+C_{R, 0}\left(x_{0} Q_{0}\right)+h_{2,0}\left(\frac{d_{1,0} t_{1,0}}{2}\right)\left(t_{2,0}\right)+h_{4,0}\left(x_{0} Q_{0}\right) T \\
+h_{1,0}\left[\frac{H_{1,0} t_{1,0}}{2}+\frac{H_{2,0}+H_{1,0}}{2}\left(t_{2,0}\right)+\frac{d_{1,0} t_{1,0}}{2}\left(t_{1,0}\right)+\sum_{i=1}^{L} H_{i}\left(t_{1, i}+t_{2, i}\right)\right]
\end{array}\right\}
$$

Substitute Eqs. (C-1) to (C-10) in Eq. (7) and take into account of the random defective rate $x_{0}$ by using the expected values of $x_{0}$, and with further derivation, $\mathrm{E}\left[T C U_{1}(T, n)\right]$ can be derived as follows:

$$
E\left[T C U_{1}(T, n)\right]=E\left[T C_{1}(T, n)\right] / E[T]=\left[C_{0} \lambda_{0}+\frac{K_{0}}{T}+C_{R, 0} \lambda_{0} E\left[x_{0}\right]+\beta_{0} T\right]
$$

where 


$$
\beta_{0}=\left\{\begin{array}{l}
\frac{h_{1,0} \lambda_{0}^{2}}{2}\left[\frac{1}{P_{1,0}}+\frac{2 E\left[x_{0}\right]}{P_{2,0}}-\frac{E\left[x_{0}\right]^{2}}{P_{2,0}}\right]+\frac{h_{2,0} \lambda_{0}^{2} E\left[x_{0}\right]^{2}}{2 P_{2,0}} \\
+h_{1,0} \sum_{i=1}^{L}\left\{\left(\frac{\lambda_{i}}{P_{1, i}}+\frac{\lambda_{i} E\left[x_{i}\right]}{P_{2, i}}\right)\left[\sum_{i=1}^{L}\left(\lambda_{i}\right)-\sum_{j=1}^{i}\left(\lambda_{j}\right)\right]\right\}+h_{4,0} \lambda_{0} E\left[x_{0}\right]
\end{array}\right\}
$$

Therefore, total relevant costs per unit time for the proposed study, $\mathrm{E}[\operatorname{TCU}(T, n)]$ is

$$
E[\operatorname{TCU}(T, n)]=E\left[T C U_{1}(T, n)\right]+E\left[T C U_{2}(T, n)\right]
$$

\subsection{The optimal production-distribution policy}

To determine the optimal production-distribution policy, one must first prove the convexity of $\mathrm{E}\left[T C U_{2}(T\right.$, $n)$ ]. Hessian matrix equations (Rardin, 1998) are employed to show the following condition hold (see Appendix D for details):

$$
\left[\begin{array}{ll}
T & n
\end{array}\right] \cdot\left(\begin{array}{ll}
\frac{\partial^{2} E\left[T C U_{2}(T, n)\right]}{\partial T^{2}} & \frac{\partial^{2} E\left[T C U_{2}(T, n)\right]}{\partial T \partial n} \\
\frac{\partial^{2} E\left[T C U_{2}(T, n)\right]}{\partial T \partial n} & \frac{\partial^{2} E\left[T C U_{2}(T, n)\right]}{\partial n^{2}}
\end{array}\right) \cdot\left[\begin{array}{l}
T \\
n
\end{array}\right]=\sum_{i=1}^{L} \frac{2 K_{i}}{T}>0
$$

Eq. (11) is positive, since $K_{\mathrm{i}}$ and $T$ are positive. So, $E\left[T C U_{2}(T, n)\right]$ is convex for all $T$ and $n$ different from zero. The following optimal operating decision can then be derived through solving the linear system of the first derivatives of $E\left[T C U_{2}(T, n)\right]$ equal to zeros (i.e., from Eqs. (D-2) and (D-4) in Appendix D):

$$
T^{*}=\sqrt{\frac{\sum_{i=1}^{L}\left(K_{i}+n K_{1, i}\right)}{\sum_{i=1}^{L}\left\{\frac{h_{1, i} \lambda_{i}^{2}}{2}\left\{\beta_{2, i}-\frac{\beta_{1, i}}{n}\right\}+\frac{h_{2, i} \lambda_{i}^{2} E\left[x_{i}\right]^{2}}{2 P_{2, i}}+\frac{h_{3, i} \lambda_{i}^{2}}{2}\left[\frac{1}{P_{1, i}}+\frac{E\left[x_{i}\right]}{P_{2, i}}+\frac{\beta_{1, i}}{n}\right]+h_{4, i} \lambda_{i} E\left[x_{i}\right]\right\}}}
$$

and

$$
n^{*}=\sqrt{\frac{\left(\sum_{i=1}^{L} K_{i}\right) \sum_{i=1}^{L}\left[\frac{\lambda_{i}^{2}}{2}\left(h_{3, i}-h_{1, i}\right)\left(\beta_{1, i}\right)\right]}{\left(\sum_{i=1}^{L} K_{1 i}\right)\left\{\sum_{i=1}^{L}\left\{\begin{array}{l}
\left.\frac{h_{1, i} \lambda_{i}^{2}}{2}\left(\beta_{2, i}\right)+\frac{h_{2, i} \lambda_{i}^{2} E\left[x_{i}\right]^{2}}{2 P_{2, i}}+h_{4, i} \lambda_{i} E\left[x_{i}\right]\right] \\
+\frac{h_{3, i} \lambda_{i}^{2}}{2}\left[\frac{1}{P_{1, i}}+\frac{E\left[x_{i}\right]}{P_{2, i}}+\frac{\beta_{1, i}}{n}\right]
\end{array}\right\}\right.}}
$$

\section{Numerical example with sensitivity analyses}

With the aim of relieving the comparison efforts, the same numerical example as in Chiu et al. (2016a) is adopted in this section to demonstrate the practical usage of our research results. The example considers a vendor fabricates five diverse finished items that share a mutual component, and which is halfway from completion (i.e., $\alpha=0.5$ ). Additional values of system parameters include the following:

\footnotetext{
$K_{i}=\$ 19,000, \$ 18,500, \$ 18,000, \$ 17,500$, and $\$ 17,000$, respectively;

$C_{i}=\$ 120, \$ 110, \$ 100, \$ 90$, and $\$ 80$, respectively;

$C_{R i}=\$ 70, \$ 65, \$ 60, \$ 55$, and $\$ 50$, respectively;
} 
$x_{i}=$ over the ranges of $[0,0.25],[0,0.20],[0,0.15],[0,0.10]$, and $[0,0.05]$, they follow uniform distribution, respectively;

$\lambda_{i}=3,800,3,600,3,400,3,200$, and 3,000 units per year, respectively;

$P_{1, \mathrm{i}}=62,000,61,000,60,000,59,000$, and 58,000 units per year, respectively;

$P_{2, i}=49,600,48,800,48,000,47,200$, and 46,400 units per year, respectively.

It is further assumed that $P_{1,0}$ has the $1 / \alpha$ relationship with $P_{1, i}$. For example, if $\alpha=0.5$, then $P_{1,0}=$ (the

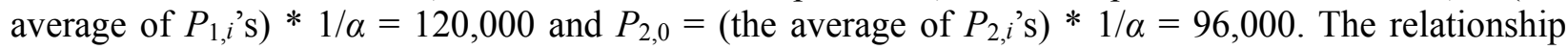
between manufacturing related cost and $\alpha$, however, could be linear or nonlinear. To show that our model is capable of exploring different relationships between manufacturing related cost of common part and $\alpha$, we conduct the following investigation respectively:

\subsection{Case 1: assuming linear relationship between cost related parameters and $\alpha$}

Case one assumes a linear relationship between manufacturing related cost for common part and $\alpha$. Accordingly, we have the following values for parameters in stage one: $K_{0}=\$ 8500, C_{0}=\$ 40, C_{\mathrm{R}, 0}=$ $\$ 25, h_{1,0}=h_{4,0}=\$ 5, h_{2,0}=\$ 15$, and $x_{0}$ over the range [0, 0.04]. Consequently, we have the following values for parameters in stage two: $C_{i}=\$ 80, \$ 70, \$ 60, \$ 50$, and $\$ 40 ; C_{R, i}=\$ 45, \$ 40, \$ 35, \$ 30$, and $\$ 25$; $x_{i}$ over the ranges $[0,0.21],[0,0.16],[0,0.11],[0,0.06]$, and $[0,0.01]$; and $K_{i}=\$ 10,500, \$ 10,000, \$ 9,500$, $\$ 9,000$, and $\$ 8,500$, respectively. $P_{1, i}=128,276,124,068,120,000,116,066$, and 112,258 (which also are based on the similar $1 / \alpha$ relationship between $P_{1, i}$ and $P_{1,0}$; i.e., $\left.P_{1, i}=1 /\left(1 / P_{1, i}-1 / P_{1,0}\right)\right)$ and $P_{2, i}=$ $102,621,99,254,96,000,92,852$, and 89,806 (similarly they are calculated by $P_{2, i}=1 /\left(1 / P_{2, i}-1 / P_{2,0}\right)$ ), respectively. Also, $K_{1 i}=\$ 2,200, \$ 2,100, \$ 2,000, \$ 1,900$, and $\$ 1,800 ; h_{1, i}=\$ 30, \$ 25, \$ 20, \$ 15$, and $\$ 10$; $h_{2, i}=\$ 50, \$ 45, \$ 40, \$ 35$, and $\$ 30 ; C_{\mathrm{T}, i}=\$ 0.5, \$ 0.4, \$ 0.3, \$ 0.2$, and $\$ 0.1 ; h_{3, i}=\$ 90, \$ 85, \$ 80, \$ 75$, and $\$ 70$; and $h_{4, i}=\$ 30, \$ 25, \$ 20, \$ 15$, and $\$ 10$, respectively. Apply equations (12), (13), and (10), the optimal fabrication-distribution decisions $n^{*}=3, T^{*}=0.4453$, and $\mathrm{E}\left[T C U\left(T^{*}, n^{*}\right)\right]=\$ 2,145,825$ can be obtained. Variations in cycle length $T$ effects on $\mathrm{E}[T C U(T, n)]$ is illustrated in Fig. 6.

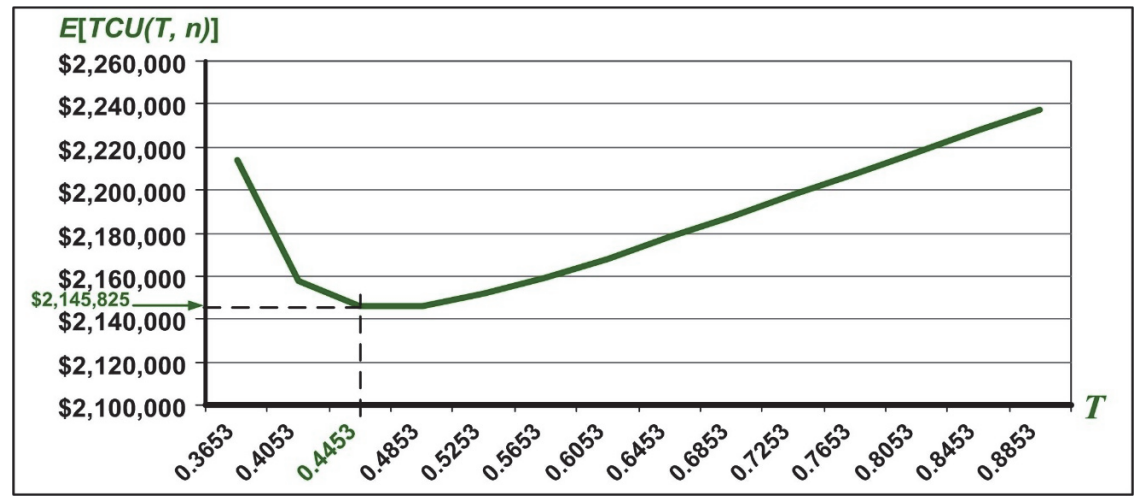

Fig. 6. Variations in cycle length $T$ effects on $\mathrm{E}[T C U(T, n)]$

Performance of $\mathrm{E}[T C U(T, n)]$ relating to completion rate $\alpha$ is depicted in Fig. 7. It is noted that as $\alpha$ raises, $\mathrm{E}[\operatorname{TCU}(T, n)]$ drops. Further analysis reveals that at $\alpha=0.5$ the proposed model realizes a system cost savings of $\$ 83,833$ (i.e., the cost declines from $\$ 2,229,658$ to $\$ 2,145,825$ ) comparing to that in a single stage fabrication system (Chiu et al., 2016b). It is also noted that $\mathrm{E}[\operatorname{TCU}(T, n)]$ is a little lower (though insignificantly) than that in Chiu et al. (2016a).

Performance of $T^{*}$ with respect to $\alpha$ for both single- and two-machine fabrication schemes is illustrated in Fig. 8. It is noted that as $\alpha$ raises, $T^{*}$ drops drastically. Analytical results further indicate the following: (A) at $\alpha=0.5, T^{*}$ has cut short $28.1 \%$ (i.e., the cycle length declines from 0.6193 to 0.4453 ) comparing to that in a single stage fabrication system (Chiu et al., 2016b); (B) at $\alpha=0.5, T^{*}$ has further reduced by 
$3.49 \%$ (i.e., from 0.4614 to 0.4453 ) comparing to that in a single-machine two-stage fabrication system (Chiu et al, 2016a). In summary, the result obtained from the proposed two-machine fabrication system offers a shorter fabrication cycle length (i.e., a rapid response time) than that in prior studies (Chiu et al., 2016a,b).

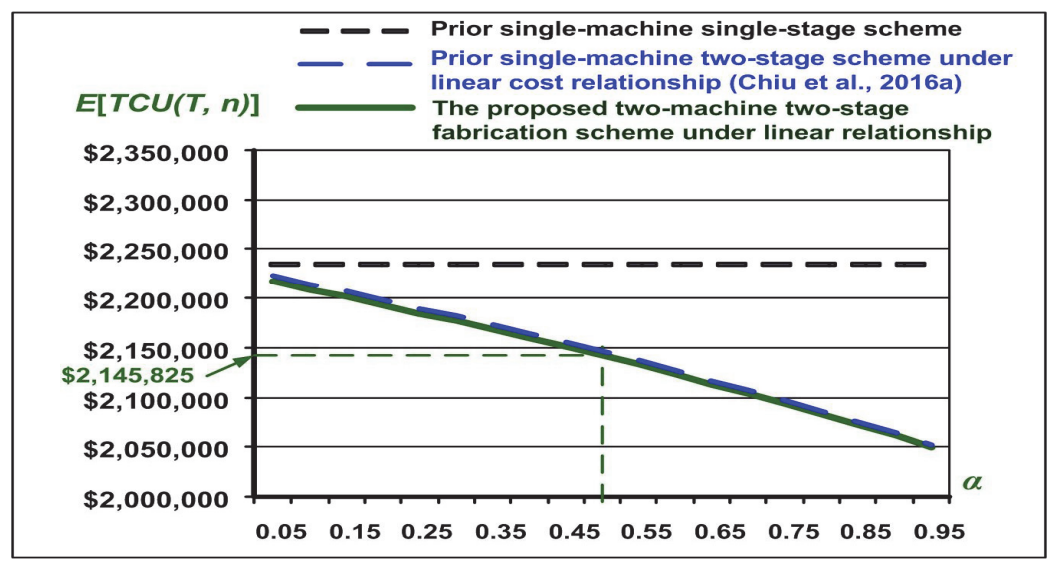

Fig. 7. Performance of $\mathrm{E}[T C U(T, n)]$ relating to $\alpha$

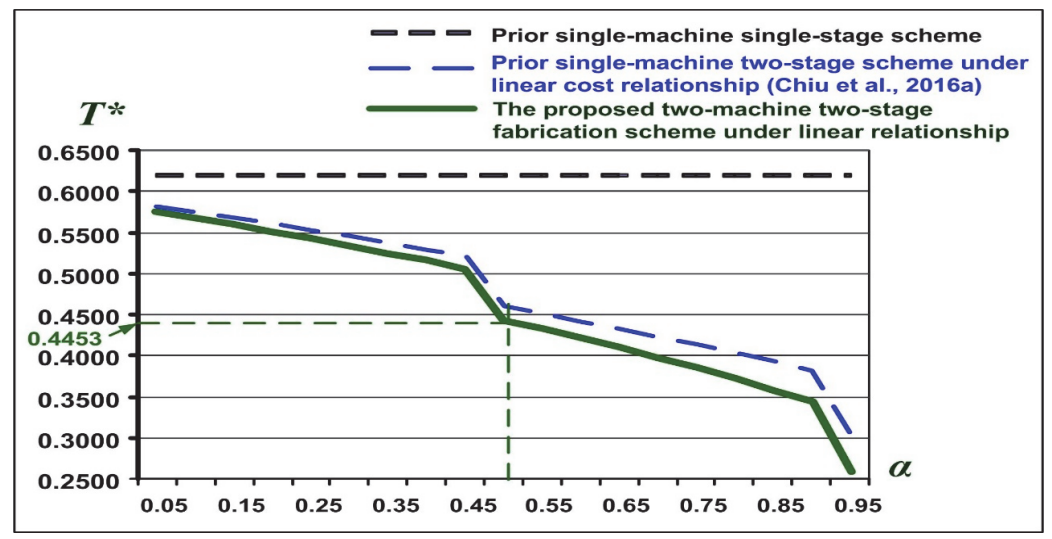

Fig. 8. Performance of $T^{*}$ with respect to $\alpha$ for both single- and two-machine fabrication schemes

\subsection{Case 2: assuming nonlinear relationship between cost related parameters and $\alpha$}

Case two assumes a nonlinear relationship between manufacturing related cost for common part and $\alpha$. For instance, a relationship of $\alpha^{\wedge}(1 / 3)$ is assumed, then the value of common part is higher than that in case one (e.g. $C_{0}=C_{1}\left(\alpha^{\wedge}(1 / 3)\right)=\$ 63>\$ 40$ (from case 1)). Accordingly, we can obtained the following values for parameters in stage one: $K_{0}=\$ 13,493, h_{1,0}=\$ 8, h_{2,0}=\$ 24, h_{4,0}=\$ 8$, and $C_{\mathrm{R}, 0}=\$ 40$. Assume the following parameters remain have the same values as in previous subsection: $x_{0}, P_{1,0}, \theta_{1,0}, x_{i}, P_{2,0}$, $\theta_{2,0}, \theta_{1, i}$, and $\theta_{2, i}$. According to the nonlinear relationship, we have the following values for parameters in stage $2: K_{i}=\$ 5,507, \$ 5,007, \$ 4,507, \$ 4,007$, and $\$ 3,507 ; C_{, i}=\$ 57, \$ 47, \$ 37, \$ 27$, and $\$ 17 ;$ and $C_{R, i}=\$ 30$, $\$ 25, \$ 20, \$ 15$, and $\$ 10$, respectively.

Apply equations (12), (13), and (10), the optimal fabrication-distribution decisions $n^{*}=3, T^{*}=0.3666$, and $\mathrm{E}\left[\operatorname{TCU}\left(T^{*}, n^{*}\right)\right]=\$ 2,094,295$ can be obtained. 


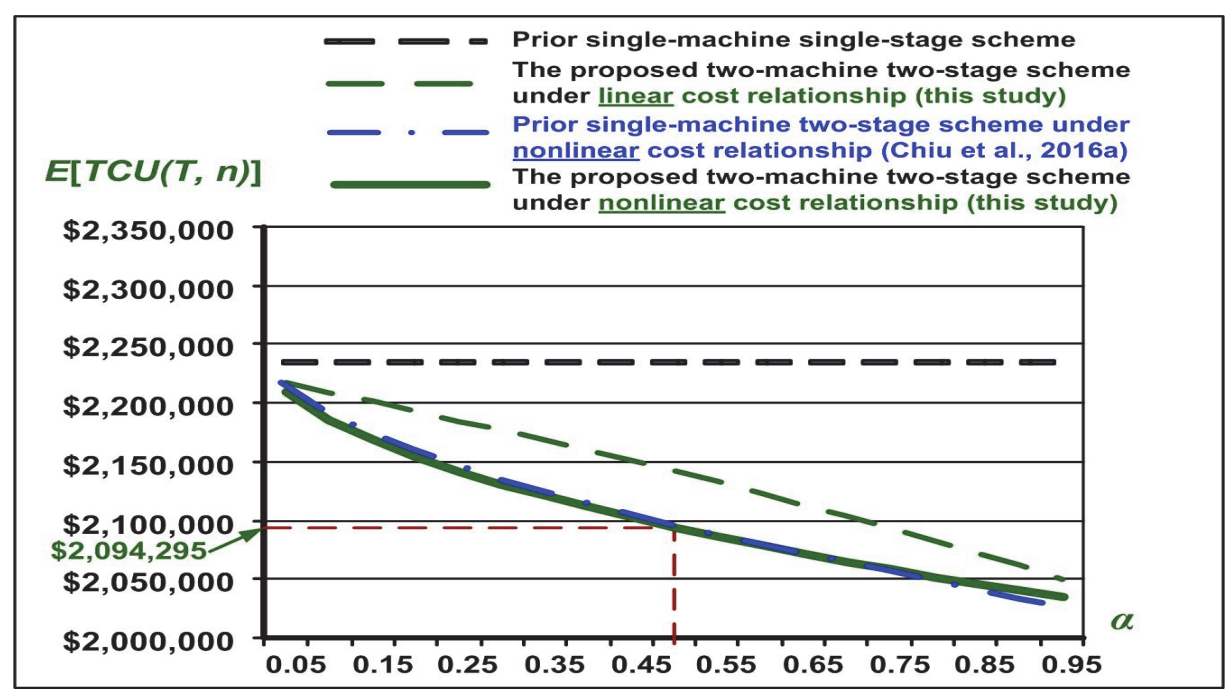

Fig. 9. Performance of $\mathrm{E}[T C U(T, n)]$ relating to $\alpha$ for both nonlinear and linear cases

Performance of $\mathrm{E}[\operatorname{TCU}(T, n)]$ relating to completion rate $\alpha$ for both nonlinear and linear cases is depicted in Fig. 9. It can be seen that as $\alpha$ raises, $\mathrm{E}[T C U(T, n)]$ declines; and $\mathrm{E}[T C U(T, n)]$ shows no considerably difference comparing to that in Chiu et al. (2016a). Analytical result further points out that (A) at $\alpha=0.5$, the proposed nonlinear case realizes a system cost savings of $\$ 135,363$ (or $6.07 \%$, for $\mathrm{E}[T C U(T, n)]$ drops from $\$ 2,229,658$ to $\$ 2,094,295$ ) comparing to that in a single stage system (Chiu et al, 2016b); (B) at $\alpha$ $=0.5$, the nonlinear case also has a savings of $\$ 51,530$ (or $2.4 \%, \mathrm{E}[T C U(T, n)]$ reduces from $\$ 2,145,825$ to $\$ 2,094,295$ ) comparing to that in the linear case (from previous subsection).

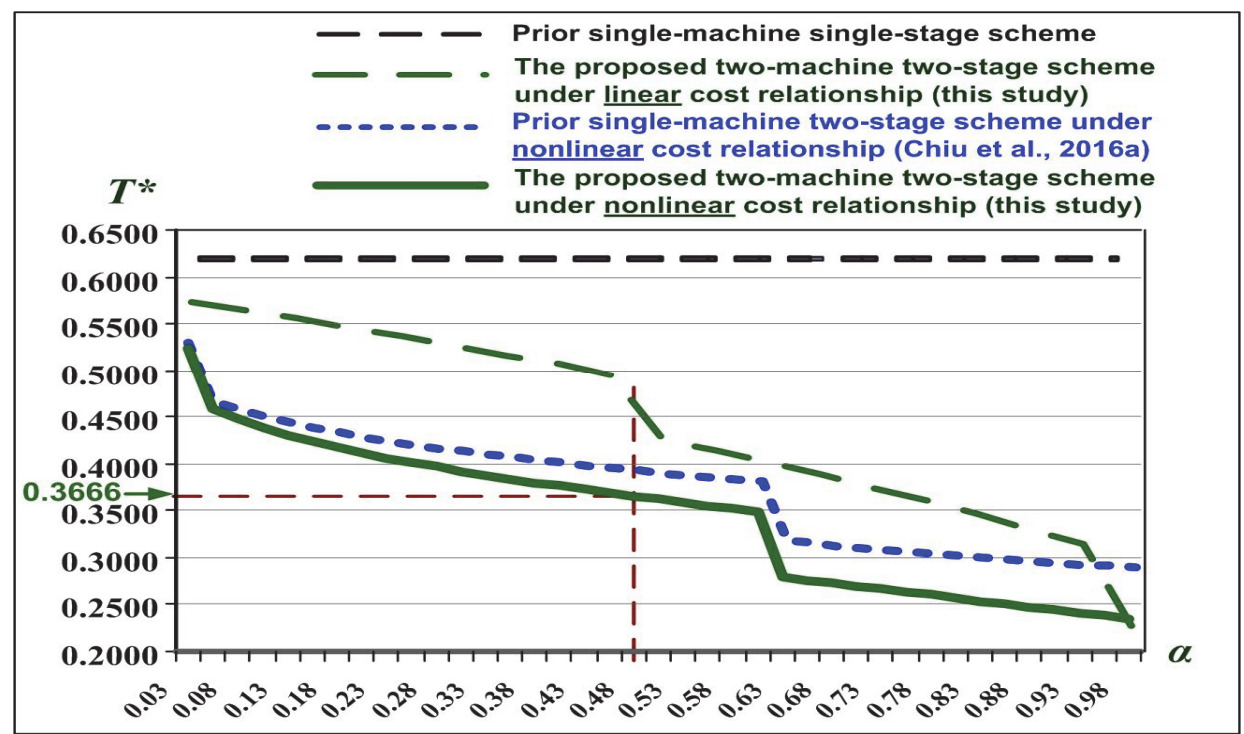

Fig. 10. Variations in $\alpha$ on $T^{*}$ for both single- and two-machine fabrication schemes under both linear and nonlinear relationships

Fig. 10 shows variations in $\alpha$ on $T^{*}$ for both single- and two-machine fabrication schemes under both linear and nonlinear relationships. It can be seen that as $\alpha$ goes up, $T^{*}$ declines notably. It is also noted that in the nonlinear case when $\alpha=0.5$, cycle length $T^{*}$ reduces by $17.7 \%$ (i.e., from 0.4453 to 0.3666 ) comparing to that in linear case. Analytical results further reveal that (A) at $\alpha=0.5, T^{*}$ is cut short by $8.5 \%$ (from 0.4005 to 0.3666 ) comparing to that in a single-machine two-stage fabrication system under 
the same nonlinear relationship (Chiu et al, 2016a); (B) also at $\alpha=0.5, T^{*}$ has a substantial $40.8 \%$ reduction (i.e., $T^{*}$ decreases from 0.6193 to 0.3666 ) vis-à-vis a prior single-machine single-stage fabrication system (Chiu et al., 2016b). The aforementioned analytical results show that the proposed system is a noticeably beneficial model (in terms of faster response time) for vendors who have to meet demands of multiproduct sharing a mutual part. Particularly, in the case that the mutual part's manufacturing related cost is high (i.e., the abovementioned nonlinear relationship case), the optimal cycle length $T^{*}$ declines drastically, comparing to that in either the case of linear relationship or a similar system using a single-machine scheme (Chiu et al., 2016a).

\section{Conclusions}

A single-machine two-stage production scheme is used in a prior study (Chiu et al., 2016a) to examine effects of delayed differentiation and rework on a multiproduct vendor-buyer integrated system. With the aim of further shortening fabrication cycle length, we propose an alternative two-machine fabrication scheme to re-explore the problem. Machine one produces just mutual components for multiple end products, and machine two fabricates the finished multiproduct using a rotation cycle length policy. Mathematical modeling along with optimization method is utilized to determine optimal cycle length and distribution decisions that minimize the expected total system costs.

Numerical examples are provided to demonstrate the practical usage of our research results. Specifically, analytical results expose the following key system performances: (1) the effects of variations in completion rate $\alpha$ on $\mathrm{E}[T C U(T, n)]$ (Fig. 7); (2) the effects of variations in $\alpha$ on the optimal cycle length $T^{*}$ for both single- and two-machine fabrication schemes (Fig. 8); (3) performance of E[TCU(T, n)] relating to $\alpha$ for both linear and nonlinear cases (Fig. 9); and (4) the effects of variations in $\alpha$ on $T^{*}$ for both single- and two-machine fabrication schemes under both nonlinear and linear relationships (Fig. 10). Clearly, without a precise and in-depth exploration, by using alternative fabrication scheme, on such a specific multiproduct supply-chain system, the aforementioned essential system characteristics are regrettably inaccessible to decision makers.

\section{Acknowledgements}

This work was supported by the Ministry of Science and Technology of Taiwan (Grant\#: MOST 1022410-H-324-015-MY2).

\section{Appendix A}

Additional notation used in this study are listed as follows (where $i=1,2, \ldots, L$, stands for product $i$ in stage two, and $i=0$ represents common intermediate part in stage one):

$K_{i}=$ production setup cost,

$C_{i}=$ unit production cost,

$C_{\mathrm{R}, i}=$ unit reworking cost,

$h_{1, i}=$ unit holding cost,

$h_{2, i}=$ holding cost per reworked item,

$h_{3, \mathrm{i}}=$ unit stock holding cost at customer's side,

$h_{4, i}=$ safety stock's unit holding cost,

$K_{1, i}=$ fixed delivery cost per shipment,

$C_{\mathrm{T}, i}=$ unit delivery cost,

$Q_{i}=$ production lot size for product $i$,

$T=$ common production cycle length - one of the decision variables,

$t_{1, i}=$ fabrication uptime,

$t_{2, i}=$ reworking time,

$t_{3, i}=$ delivery time, 
$t_{\mathrm{n}, i}=$ a fixed interval of time between two consecutive shipments in $t_{3, i}$,

$n=$ number of deliveries per cycle, the other decision variable,

$\alpha=$ completion rate of common part as compared to the finished product,

$H_{i}=$ level of common part at the time of fabrication end item $i$,

$H_{1, i}=$ level of finished product $i$ in the end of uptime,

$H_{2, \mathrm{i}}=$ level of finished product $i$ in the end of reworking time,

$D_{\mathrm{i}}=$ number of end product $i$ to be transported in each shipment,

$\mathrm{E}[T]=$ the expected cycle time,

$T C_{1}(T, n)=$ total fabrication-shipment relevant cost in a cycle for stage 1 ,

$\mathrm{E}\left[T C_{1}(T, n)\right]=$ the expected total fabrication-shipment relevant cost in a cycle for stage 1 , $\mathrm{E}\left[T C U_{1}(T, n)\right]=$ expected total fabrication-shipment relevant cost per unit time for stage 1 ,

$T C_{2}(T, n)=$ total fabrication-shipment relevant cost in a cycle for stage 2 ,

$\mathrm{E}\left[T C_{2}(T, n)\right]=$ the expected total fabrication-shipment relevant cost in a cycle for stage 2 ,

$\mathrm{E}\left[\operatorname{TCU}_{2}(T, n)\right]=$ expected total fabrication-shipment relevant cost per unit time for stage 2,

$\mathrm{E}[T C U(T, n)]=$ the expected system cost per unit time for the proposed model.

\section{Appendix B}

In stage two, the following basic formulas can be observed directly from Figs. 2 to 5 (where $i=1$, $2, \ldots, L)$ :

$Q_{i}=\lambda_{i} T$

$Q_{i}=P_{1, i}\left(t_{1, i}\right)$

$H_{1, i}=\left(P_{1, i}-d_{1, i}\right) t_{1, i}$

$H_{2, i}=H_{1, i}+P_{2, i} t_{2, i}$

$t_{1, i}=\frac{Q_{i}}{P_{1, i}}=\frac{H_{1, i}}{P_{1, i}-d_{1, i}}$

$t_{2, i}=\frac{x_{i} Q_{i}}{P_{2, i}}=\frac{d_{1, i} t_{1, i}}{P_{2, i}}=\frac{H_{2, i}-H_{1, i}}{P_{2, i}}$

$t_{3, i}=n t_{n, i}$

$d_{1, i} \cdot t_{1, i}=P_{1, i} x_{i} \cdot t_{1, i}$

$T=t_{1, i}+t_{2, i}+t_{3, i}=\frac{Q_{i}}{\lambda_{i}}$

$D_{i}=\frac{H_{2, i}}{n}$

$I_{i}=D_{i}-\lambda_{i} t_{n, i}$

$n I_{i}=\lambda_{i}\left(t_{1, i}+t_{2, i}\right)$

The inventory holding cost for items waiting to be reworked in stage two is (Fig. 3)

$\sum_{i=1}^{L}\left[h_{2, i}\left(\frac{P_{2, i} t_{2, i}}{2}\right)\left(t_{2, i}\right)\right]$

The holding cost for common stocks waiting to be processed into finished goods (Fig. 4) is

$\sum_{i=1}^{L}\left\{h_{1, i}\left[\frac{Q_{i}}{2}\left(t_{1, i}\right)\right]\right\}$

In delivery time $t_{3, i}$, fixed and variable transportation costs and holding cost for $L$ end products awaiting to be shipped to customer is

$$
\sum_{i=1}^{L}\left[n K_{1, i}+C_{T, i} Q_{i}\right]+\sum_{i=1}^{L}\left[h_{1, i}\left(\frac{n-1}{2 n}\right) H_{2, i} t_{3, i}\right]
$$


The stock holding cost at customers' sides (see Fig. 5) per cycle is

$\sum_{i=1}^{L}\left\{h_{3, i}\left[\frac{n\left(D_{i}-I_{i}\right) t_{n, i}}{2}+\frac{n(n+1)}{2} I_{i} t_{n, i}+\frac{n I_{i}\left(t_{1, i}+t_{2, i}\right)}{2}\right]\right\}$

\section{Appendix C}

In stage one, the following basic formulas can be observed directly from Figs. 1, 3, and 4:

$$
\begin{aligned}
& Q_{0}=\sum_{i=1}^{L} Q_{i}=\lambda_{0} T \\
& H_{1,0}=t_{1,0}\left(P_{1,0}-d_{1,0}\right) \\
& H_{2,0}=H_{1,0}+P_{2,0} t_{2,0} \\
& t_{1,0}=\frac{Q_{0}}{P_{1,0}}=\frac{H_{1,0}}{P_{1,0}-d_{1,0}} \\
& t_{2,0}=\frac{x_{0} Q_{0}}{P_{2,0}}=\frac{d_{1,0} t_{1,0}}{P_{2,0}}=\frac{H_{2,0}-H_{1,0}}{P_{2,0}} \\
& H_{2,0}=\sum_{i=1}^{L} Q_{i} \\
& H_{1}=H_{2,0}-Q_{1} \\
& H_{i}=H_{(i-1)}-Q_{i} \text { for } i=2,3, \ldots, L \\
& H_{L}=H_{(L-1)}-Q_{L}=0 \\
& T=t_{1,0}+t_{2,0}+t_{3,0}=\frac{Q_{0}}{\lambda_{0}}
\end{aligned}
$$

\section{Appendix D}

Apply Hessian matrix equations (Rardin, 1998) to $\mathrm{E}\left[T C U_{2}(T, n)\right]$ to show the following condition must hold.

$$
\left[\begin{array}{ll}
T & n
\end{array}\right] \cdot\left(\begin{array}{ll}
\frac{\partial^{2} E[T C U(T, n)]}{\partial T^{2}} & \frac{\partial^{2} E[T C U(T, n)]}{\partial T \partial n} \\
\frac{\partial^{2} E[T C U(T, n)]}{\partial T \partial n} & \frac{\partial^{2} E[T C U(T, n)]}{\partial n^{2}}
\end{array}\right) \cdot\left[\begin{array}{l}
T \\
n
\end{array}\right]>0
$$

Accordingly, we have the following:

$$
\begin{aligned}
& \frac{\partial E\left[T C U_{2}(T, n)\right]}{\partial T}=\sum_{i=1}^{L}\left\{\begin{array}{l}
{\left[\frac{-K_{i}}{T^{2}}-\frac{n K_{1, i}}{T^{2}}\right]+\frac{h_{1, i} \lambda_{i}^{2}}{2}\left\{\beta_{2, i}-\frac{\beta_{1, i}}{n}\right\}+h_{4, i} \lambda_{i} E\left[x_{i}\right]} \\
+\frac{h_{3, i} \lambda_{i}^{2}}{2}\left[\frac{1}{P_{1, i}}+\frac{E\left[x_{i}\right]}{P_{2, i}}+\frac{\beta_{1, i}}{n}\right]+\frac{h_{2, i} \lambda_{i}^{2} E\left[x_{i}\right]^{2}}{2 P_{2, i}}
\end{array}\right\} \\
& \frac{\partial E\left[T C U_{2}(T, n)\right]}{\partial T^{2}}=\sum_{i=1}^{L}\left\{\frac{2 K_{i}}{T^{3}}+\frac{2 n K_{1, i}}{T^{3}}\right\} \\
& \frac{\partial E\left[T C U_{2}(T, n)\right]}{\partial n}=\sum_{i=1}^{L}\left\{\frac{K_{1, i}}{T}+\frac{T \lambda_{i}^{2}}{2 n^{2}}\left[\left(h_{1, i}-h_{3, i}\right)\left(\beta_{1, i}\right)\right]\right\} \\
& \frac{\partial E\left[T C U_{2}(T, n)\right]}{\partial n^{2}}=\sum_{i=1}^{L}\left\{\frac{T \lambda_{i}^{2}}{n^{3}}\left[\left(h_{3, i}-h_{1, i}\right)\left(\beta_{1, i}\right)\right]\right\} \\
& \frac{\partial^{2} E\left[T C U_{2}(T, n)\right]}{\partial T \partial n}=\sum_{i=1}^{L}\left\{-\frac{K_{1, i}}{T^{2}}+\frac{\lambda_{i}^{2}}{2 n^{2}}\left[\left(h_{1, i}-h_{3, i}\right)\left(\beta_{1, i}\right)\right]\right\}
\end{aligned}
$$


Substitute Eqs. (D-3), (D-5), and (D-6) in Eq. (D-1) and with further derivations we obtain the following (which is the same as Eq. (11)):

$$
\left[\begin{array}{ll}
T & n
\end{array}\right] \cdot\left(\begin{array}{ll}
\frac{\partial^{2} E\left[T C U_{2}(T, n)\right]}{\partial T^{2}} & \frac{\partial^{2} E\left[T C U_{2}(T, n)\right]}{\partial T \partial n} \\
\frac{\partial^{2} E\left[T C U_{2}(T, n)\right]}{\partial T \partial n} & \frac{\partial^{2} E\left[T C U_{2}(T, n)\right]}{\partial n^{2}}
\end{array}\right) \cdot\left[\begin{array}{l}
T \\
n
\end{array}\right]=\sum_{i=1}^{L} \frac{2 K_{i}}{T}>0 .
$$

\section{References}

Aliyu, M.D.S., \& Andijani, A.A. (1999). Multi-item-multi-plant inventory control of production systems with shortages/backorders. International Journal of Systems Science, 30(5), 533-539.

Archetti, C., Doerner, K.F., \& Tricoire, F. (2013). A heuristic algorithm for the free newspaper delivery problem. European Journal of Operational Research, 230(2), 245-257.

Balaji, M., Velmurugan, V., \& Subashree, C. (2015). TADS: An assessment methodology for agile supply chains. Journal of Applied Research and Technology, 13(5), 504-509.

Bernstein, F., DeCroix, G.A., \& Wang, Y. (2011). The impact of demand aggregation through delayed component allocation in an assemble-to-order system. Management Science, 57(6), 1154-1171.

Boorla, S.M., \& Howard, T.J. (2016). Production monitoring system for understanding product robustness. Advances in Production Engineering \& Management, 11(3), 159-172.

Caggiano, K.E., Jackson, P.L., Muckstadt, J.A., \& Rappold, J.A. (2009). Efficient computation of timebased customer service levels in a multi-item, multi-echelon supply chain: A practical approach for inventory optimization. European Journal of Operational Research, 199(3), 744-749.

Chiu, S.W., Huang, C-C., Chiang, K-W., \& Wu, M-F. (2015). On intra-supply chain system with an improved distribution plan, multiple sales locations and quality assurance. SpringerPlus, 4(1), article number 687, 1-11.

Chiu, Y-S.P., Kuo, J-S., Chiu, S. W., \& Hsieh, Y-T. (2016a). Effect of delayed differentiation on a multiproduct vendor-buyer integrated inventory system with rework. Advances in Production Engineering \& Management, 11(4), 333-344.

Chiu, Y-S.P., Chiang, K-W., Chiu, S.W., \& Song, M-S. (2016b). Simultaneous determination of production and shipment decisions for a multi-product inventory system with a rework process. Advances in Production Engineering \& Management, 11(2), 141-151.

Chiu, S.W., Kuo, J-S., Chiu, V., \& Chiu, Y-S.P. (2016c). Cost minimization for a multi-product fabrication-distribution problem with commonality, postponement, and quality assurance. Mathematical \& Computational Applications, 21(3), article number 38.

Collier, D.A. (1982). Aggregate safety stock levels and component part commonality. Management Science, 28(11), 1296-1303.

Fergany, H.A. (2016). Probabilistic multi-item inventory model with varying mixture shortage cost under restrictions. SpringerPlus, 5(1), article number 1351.

Ferreira, K.A., Tomas, R.N., \& Alcântara, R.L.C. (2015). A theoretical framework for postponement concept in a supply chain. International Journal of Logistics Research \& Applications, 18(1), 46-61.

Gerchak, Y., \& Henig, M. (1986). An inventory model with component commonality. Operations Research Letters, 5(3), 157-160.

Gómez, J., Salazar, I., \& Vargas, P. (2016). Sources of information as determinants of product and process innovation. PLoS ONE, 11(4), article number e 0152743.

Graman, G.A., \& Magazine, M.J. (2002). A numerical analysis of capacitated postponement, Production \& Operations Management, 11(3), 340-356.

Graman, G.A., \& Magazine, M.J. (2006). Implementation issues influencing the decision to adopt postponement. International Journal of Operations \& Production Management, 26(10), 1068-1083.

Guerrero, W.J., Yeung, T.G., \& Guéret, C. (2013). Joint-optimization of inventory policies on a multiproduct multi-echelon pharmaceutical system with batching and ordering constraints, European Journal of Operational Research, 231(1), 98-108. 
Gupta, D., \& Benjaafar, S. (2004). Make-to-order, make-to-stock, or delay product differentiation? A common framework for modeling and analysis. IIE Transactions, 36(6), 529-546.

Henig, M., \& Gerchak, Y. (1990). Structure of periodic review policies in the presence of random yield. Operations Research, 38(4), 634-643.

Hillier, F.S., \& Lieberman, G.J. (2001). Introduction to Operations Research, McGraw Hill: New York. Jawla, P., \& Singh, S.R. (2016). Multi-item economic production quantity model for imperfect items with multiple production setups and rework under the effect of preservation technology and learning environment. International Journal of Industrial Engineering Computations, 7(4), 703-716.

Karunambigai S, Geetha K, \& Shabeer HA. (2015). Power Quality Improvement of Grid Connected Solar System. Journal of Scientific \& Industrial Research, 74(6), 354-357.

Kundu, S., \& Chakrabarti, T. (2015). An integrated multi-stage supply chain inventory model with imperfect production process. International Journal of Industrial Engineering Computations, 6(4), $565-580$.

Lee, H.L. (1996). Effective inventory and service management through product and process redesign. Operations Research, 44(1), 151-159.

Ma, W-N., Gong, D-C., \& Lin, G.C. (2010). An optimal common production cycle time for imperfect production processes with scrap. Mathematical \& Computer Modelling, 52(5-6), 724-737.

Nahmias, S. (2009). Production \& Operations Analysis, McGraw-Hill Inc, New York.

Rahim, M.A., \& Ben-Daya, M. (2001). Joint determination of production quantity, inspection schedule and quality control for imperfect process with deteriorating products. Journal of the Operational Research Society, 52(12), 1370-1378.

Rardin, R.L. (1998). Optimization in Operations Research, Prentice-Hall, New Jersey.

Reimann, M. (2012). Accurate response by postponement. European Journal of Operational Research, 220(3), 619-628.

Rosenblatt, M.J., \& Rothblum, U.G. (1990).On the single resource capacity problem for multi-item inventory systems. Operations Research, 38(4), 686-693.

Sarker, B.R., \& Parija, G.R. (1994). An optimal batch size for a production system operating under a fixed-quantity, periodic delivery policy. Journal of the Operational Research Society, 45(8), 891900.

Schwarz, L.B., Deuermeyer, B.L., \& Badinelli, R.D. (1985). Fill-rate optimization in a one- warehouse $\mathrm{N}$-identical retailer distribution system. Management Science, 31(4), 488-498.

Swaminathan, J.M., \& Tayur, S.R. (1998). Managing broader product lines through delayed differentiation using vanilla boxes. Management Science, 44(12), S161-S172.

Swaminathan, J.M., \& Tayur, S.R. 1999. Managing design of assembly sequences for product lines that delay product differentiation. IIE Transactions, 31(11), 1015-1026.

Thomas, D.J., \& Hackman, S.T. (2003). A committed delivery strategy with fixed frequency and quantity. European Journal of Operational Research, 148(2), 363-373.

Weber, T.A. (2008). Delayed multiattribute product differentiation. Decision Support Systems. 44(2), 447-468.

Zahedi, Z., Ari Samadhi, T.M.A., Suprayogi, S., \& Halim, A.H. (2016). Integrated batch production and maintenance scheduling for multiple items processed on a deteriorating machine to minimize total production and maintenance costs with due date constraint. International Journal of Industrial Engineering Computations, 7(2), 229-24.

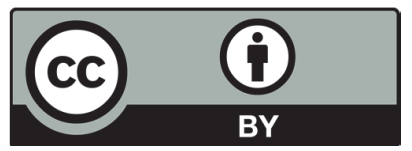

(C) 2017 by the authors; licensee Growing Science, Canada. This is an open access article distributed under the terms and conditions of the Creative Commons Attribution (CCBY) license (http://creativecommons.org/licenses/by/4.0/). 